\section{Extraneural competition between different scrapie agents leading to loss of infectivity}

MANY strains of scrapie agent have been isolated which differ in their biological properties, such as incubation period and type of brain lesion ${ }^{1}$. We have shown previously that competition occurred between different scrapie agents intracerebrally injected into mice ${ }^{2}$, indicated by an increase in the incubation period of the lethal scrapie agent when a different scrapie agent had also been injected to impede its pathogenesis. We did not establish whether the increased incubation resulted from replication of the lethal agent being hindered throughout or at particular stages of pathogenesis, or whether the increased incubation period resulted from some loss of effective titre.

The pathogenesis of different scrapie agents injected into mice can only be described as relatively 'quick' or 'slow' if the recipient mouse genotype is specified in terms of the gene sinc (alleles s7 and p7). On this basis, inbred mice can be injected with a 'slow' agent which can block, partially or completely, the pathogenesis of a 'quick' agent injected later by the same route. We have previously found that the effectiveness of blocking depends on the route of injection, the interval between injections and the particular strains and doses of agent used. We show that agent competition can be so effective in some circumstances that the 'quicker' agent, injected later, seems to take no active part in the disease and may have been entirely degraded or excreted.

RIII mice ( $3-4$ weeks old) were injected intraperitoneally with either brain homogenate containing $22 \mathrm{~A}$ agent, or with a similar dose of normal VM brain as controls. All mice received a second intraperitoneal injection of brain homogenate containing $22 \mathrm{C}$ agent, given either 100,200 or 300 days after $22 \mathrm{~A}$ (Table 1). The expected incubation periods for $22 \mathrm{~A}$ and $22 \mathrm{C}$ given singly in these doses would be 550 days and 230 days, respectively. To calculate incubation periods when two agents are injected, we must be able to determine which agent eventually kills the mouse or, even, whether both share in this process. $22 \mathrm{~A}$ and $22 \mathrm{C}$ are quite different in the intensity and distribution of brain lesions which they produce (ref. 3 and H.F., unpublished), and consequently the 'lesion profile' for each group in the competition experiment can be used to decide which origin to use for calculating incubation periods.

Table 1 Scrapie in RIIIrorosincs ${ }^{757}$ mice injected intraperitoneally either with two different scrapie agents or with only one agent; the interval between injection of the two agents was varied

\begin{tabular}{|c|c|c|c|c|}
\hline $\begin{array}{l}\text { First injection: } \\
\text { Second injection: }\end{array}$ & \multicolumn{2}{|c|}{$\begin{array}{c}\text { Normal brain } \\
22 \mathrm{C}\end{array}$} & \multicolumn{2}{|r|}{$\begin{array}{l}22 \mathrm{~A} \\
22 \mathrm{C}\end{array}$} \\
\hline Injection & $\begin{array}{l}\text { Brain } \\
\text { lesion }\end{array}$ & Incubation & Brain & Incubation \\
\hline $\begin{array}{l}\text { interval } \\
\text { (days) }\end{array}$ & $\begin{array}{l}\text { profile } \\
\text { type }\end{array}$ & $\begin{array}{c}\text { period } \\
\text { (days }+ \text { s.e.) }\end{array}$ & $\begin{array}{l}\text { profile } \\
\text { type }\end{array}$ & $\begin{array}{c}\text { period } \\
\text { (days } \pm \text { s.e.) }\end{array}$ \\
\hline 100 & $22 \mathrm{C}$ & $237 ! \pm 6(7)$ & $22 \mathrm{~A}$ & $554 \pm 13(6)$ \\
\hline 200 & $22 \mathrm{C}$ & $232 \pm 2(7)$ & $22 \mathrm{~A}$ & $557 \pm 5$ (9) \\
\hline 300 & $22 \mathrm{C}$ & $231+0(5)$ & $22 \mathrm{~A}$ & $561 \pm 7$ \\
\hline
\end{tabular}

Number of mice in parenthesis. Doses: $22 \mathrm{~A}$ agent $-0.02 \mathrm{ml}$ of $10^{-1}$ saline homogenate from $22 \mathrm{~A}$-infected $\mathrm{VM}$ brain, containing $10^{5} \mathrm{VM}$ intracerebral $\mathrm{LD}_{50}$ units $0.02 \mathrm{ml}^{-1} .22 \mathrm{C}$ agent $-0.02 \mathrm{ml}$ supernatant $(2,000 \mathrm{~g}$ for $15 \mathrm{~min})$ of $10^{-2}$ saline homogenate from $22 \mathrm{C}$-infected $\mathrm{C} 57 \mathrm{BL}$ brain, containing $10^{3.7} \mathrm{C} 57 \mathrm{BL}$ intracerebral $\mathrm{LD}_{50}$ units $0.02 \mathrm{ml}^{-1}$.

Table 1 shows that the $22 \mathrm{~A}$ blocking injection was so effective that the second injection (22C) failed to infect the mice. The lesion profiles for the blocked and control groups are significantly different (method of least squares; $P<0.001$ ) and the profile in the blocked animals confirms that $22 \mathrm{~A}$ was responsible for killing the mice. If $22 \mathrm{C}$ does take an active part in the disease in the blocked groups, atthough subsidiary to $22 \mathrm{~A}$, we would expect variation between the results for the three sub- groups with different intervals between injections: there was no evidence of such differences (incubation period $P>0.6$; lesion profile $P>0.35$ ). We do not yet have titration estimates in RIII mice of the number of intraperitoneal $L_{50}$ units of $22 \mathrm{~A}$ and $22 \mathrm{C}$ but the doses were at least $10^{1.5}$ and $10^{2}$, respectively.

We regarded this as further support for the scrapie replication site hypothesis ${ }^{4}$, which proposes that replication of scrapie agents depends on a multimeric host site, to which different types of subunit are contributed by the two alleles of sinc, that there is a limit on the total available number of replication sites and that this total is relatively small. Agent competition is therefore envisaged as resulting from the agent injected first, having had the opportunity to occupy some or all the available sites, and thus blocking the access of agent injected later, even though the latter may be a much 'quicker' agent than the one already there. The total efficiency of blocking achieved in the above experiment also indicates that the rate of site turnover is low, and that production of new sites must be infrequent, unless the blocking agent has priority in access to them. The low turnover implies that the agent occupying the sites, and presumably also replicated there, must not, at any stage of the replication process vacate the sites, even transiently, to allow access of agent injected later.

Competition between scrapie agents able to replicate in mice, raises the question of whether site blocking could be achieved using related agents which do not seem to replicate in mice, such as the agents of kuru, Creutzfeldt-Jakob disease or transmissible mink encephalopathy. It may even be possible to block sites with simpler, non-replicating, molecules. To be of practical use in the control of such diseases, however, it must be assumed that the sites which these agents use are not essential to the normal health of the animal.
A. G. DiCKINSON
H. FrASER
IRENE MCCONNELL
G. W. OUtram
D. I. Sales
D. M. TAYLOR

ARC Animal Breeding Research Organisation,

West Mains Road,

Edinburgh EH9 $3 J Q$ and

Moredun Research Institute,

Edinburgh EHI7 $7 \mathrm{JH}, \mathrm{UK}$

Received November 22, 1974

1 Dickinson, A. G., Genetics (in the press)

Dickinson, A. G., Fraser, H., Meikle, V.M. H. and Outram, G. W. Nature new Biol., 237, 244 (1972).

A. G. $f_{1}(0), P u h .83,29$ (1973).

4 Dickinson, A. G., and Meikle, V. M. H., Molec. gen. Ginet, 112, 73 (1971).

\section{Relaxing and inotropic effects of cyclic AMP on skinned cardiac cells}

THE positive inotropic effect of catecholamines in cardiac muscle is assumed to result from an increase in the intracellular level of cyclic AMP (adenosine 3',5'-monophosphate) ${ }^{1,2}$. Cyclic AMP may enhance the contraction by increasing the trans-sarcolemmal flux of $\mathrm{Ca}^{2}{ }^{2}$ during the plateau of the action potential ${ }^{3.4}$, but the flux seems insufficient to activate directly the myofilaments and it is generally assumed that additional $\mathrm{Ca}^{2+}$ may be released from intracellular stores (ref, 5), possibly by a $\mathrm{Ca}^{2}{ }^{2}$-triggered release from the sarcoplasmic reticulum $(\mathrm{SR})^{6-8}$.

Whether the intracellular level of cyclic AMP can modulate this release of $\mathrm{Ca}^{2+}$ is not known. Furthermore, catecholamines increase the rate of relaxation in the intact myocardial tissue $e^{9}$. How cyclic AMP could mediate this relaxing effect has not been established, although studies in isolated cardiac microsomes suggest that cyclic AMP may enhance $\mathrm{Ca}^{2+}$ binding by the 